\title{
Hydraulics CHARACTERISTICS OF FLOW OVER CONTRACTED CLEAR OVERFALL WEIRS WITH BOTTOM-PIPES \\ Gamal Abozeid ${ }^{1, *}$, Ahmed M. El-Belasy ${ }^{2}$ and Salah M. Shehata ${ }^{3}$ \\ 1, *Vice Dean Prof., Civil Eng. Dept., Assiut Univ., Assiut, Egypt. \\ ${ }^{2}$ Associate Prof., Hydraulics Research Institute, National Water Research Center, Egypt. \\ ${ }^{3}$ Doctorate Student, Civil Eng. Dept., Assiut Univ., Assiut, Egypt.
}

Received 25 December 2013; revised 16 January 2014; accepted 26 January 2014 ABSTRACT

Fayoumi Standard Weirs have been modified by adding one, two or three pipes, to convey much water to downstream direction. Measurements of discharge with these structures are complicated due to existence of the openings. In this research, an experimental study is carried out to investigate the effect of installing pipes through a piped clear over fall weir and bottom-pipes. Twelve weir models with different heights are tested in horizontal laboratory flume of $17 \mathrm{~m}$ length, $0.3 \mathrm{~m}$ width, and $0.5 \mathrm{~m}$ depth. Weir height is changed two times. Contraction of weirs is changed two times. For each one, the diameter of opening is changed three times. The downstream depth is changed to cover all the concerned flow regimes of flow rate for a submerged pipe and a free weir. The downstream water depth begins with the upper tangent of the pipe and ends with the crest level of the weir. The contraction and the un-contraction of the weir are discussed. The effect of downstream water depth is taken into consideration. The results of flow over weir with opening are compared with those of weir without opening having the same dimensions. It is found that there is a large difference between them. Multiple regression equations based on energy principal and dimensional analysis theory are developed for computing discharge over clear over fall weir with bottom pipes. Also, values of discharge coefficients were estimated for combined flow over the weir and through the pipe. Then the total discharge can be computed by multiplying the discharge coefficient by the summation of theoretical weir discharge plus theoretical orifice discharge. Equations for computing the discharge of combination are awarded.

Keywords: Fayoumi weir, bottom pipes, free discharge, discharge coefficient, contracted and un-contracted piped-weirs.

\section{Introduction}

Weirs are typically installed in open channels to measure the flow rates. The basic principle is that discharge is directly related to the acting head on the weir $(\mathrm{H})$. Rectangular weirs can be suppressed, partially or fully contracted. A suppressed weir's width (b) is equal to the channel width (B); thus, there really isn't a notch - the weir is flat all the way along the top. For a weir to be fully contracted, (B-b) must be greater than $4 \mathrm{H}_{\max }$, where $\mathrm{H}_{\max }$ is the maximum expected head on the weir [21]. A partially contracted weir has B-b between 0 and $4 \mathrm{H}_{\max }$. Weir contractions cause the water flow lines to converge through the notch.

With the increase of cultivated area served by canals, water demands becoming higher. As a result the capacity of the existing weirs built on those canals and the embankment of the canals themselves upstream of the weirs becoming insufficient to pass this increase of

\footnotetext{
* Corresponding author.

E-mail address: gabozeid@yahoo.com
} 
high water demands. So, the solution is to replace the old structures by new ones or to modify the existing ones. The first solution is costly prohibitive while the second requires a modification of the hydraulics of the weirs. The modifications may be the widening or lowering weir crest or operating the existing pipes used at the bottom for emptying the canals to pass extra flow rates to downstream.

Clear over fall weirs are common engineering structures in irrigation system in Egypt, especially in Fayoum district. The name "Fayoum standard weir" became worldwide known [1]. Wolters et al. [18] made serious attempts to calculate the discharge for system consisted of a specific weir and a pipe. They made a distinction between flow over the weir, which can be calculated rather accurate, and the flow through the pipes, which is far less reliable. They suggested rating curves for all weirs they studied.

Abdel halim et al. [1] calibrated experimentally the flow over existing Fayoum weirs with orifices. They suggested that, calibration must be based only on water head over the crest of the weir $H$, which is the only measurable parameter in the field. They introduced equation for computing the discharge, but they showed that this equation is based on the dimensions of the model used in their work. Therefore, it can not be used as a general case in the field. Negm [10-12] conducted extensive experimental studies on the characteristics of combined flow over sharp-edged and below a gate with different shapes and different flow conditions and introduced a general dimensionless relationships for predicting the discharge of the combined flow through these structures. Abouzeid et al. [3] conducted experiments on the flow characteristics of uncontracted clear over fall weir with bottom pipes managed to analyze the complicated flow. They found that the downstream water depth affects the upstream water depth for weir with opening when the openings become submerged.

In a study conducted by El-Belasy, A.M. [9], formulas were established for rehabilitated weirs (modified weirs with 1 or 2 pipes in their bodies to allow more water to pass) in order to assist engineers in the design process. Several site visits were carried out to the existing rehabilitated weirs in El-Fayoum.

It is noticed that most of previous works for discharge measurement structures were carried out on weirs without pipe or on sharp crested weirs with non-circular openings or on un-contracted piped weirs. However, in irrigation system, like the Fayoum irrigation system, weirs are not sharp crested, depressed (un-contracted) and are fed by circular opening. The main purpose of this research is to determine the relationship between the flow passing through the pipe and over the contracted weir to know how much the pipe can affect the flow passing over the weir.

\section{Laboratory experiments}

Laboratory experiments were carried out in an open channel glass side tilting flume type. At the outlet of the flume, there is a tailgate to regulate water levels. In all of experiments, discharge was regulated by a gate valve and was measured by an orifice meter fitted to a pipeline which feeds water to the flume. Water surface profile and water levels were obtained using a point gauge. 
Twelve models have been built from sand-cement mortar with different heights and openings made of PVC pipes. Six of them are contracted by using two side walls of width $4.9 \mathrm{~cm}$ for each. Figure (1) shows definition sketch of the models used in the experiments, and Photo (1) shows a view of the used channel. The experiments were conducted for various ranges of weir height $\mathrm{P}$, opening diameter $\mathrm{D}$, discharge $\mathrm{Q}$ and downstream water depth $\mathrm{y}_{2}$. Ranges of experimental parameters are listed in Table (1).

Table 1.

Experimental conditions and ranges.

\begin{tabular}{|l|c|c|c|c|c|}
\hline \multirow{2}{*}{ Parameter } & \multirow{2}{*}{ Symbol } & \multirow{2}{*}{ Value } & \multicolumn{2}{c|}{ Range } & \multirow{2}{*}{ Units } \\
\cline { 4 - 5 } & & & From & To & \\
\hline Height of weir. & $\mathrm{P}$ & $14.6,20.0$ & 14.6 & 20.0 & $\mathrm{~cm}$. \\
\hline Width of weir. & $\mathrm{b}$ & $20.2,30.0$ & 20.2 & 30.0 & $\mathrm{~cm}$. \\
\hline Diameter of pipe. & $\mathrm{D}$ & $4.5,5.4,7.0$ & 4.5 & 7.0 & $\mathrm{~cm}$. \\
\hline Upstream water depth. & $\mathrm{y}_{1}$ & varied & 13.40 & 28.45 & $\mathrm{~cm}$. \\
\hline Downstream water depth. & $\mathrm{y}_{2}$ & varied & 9.1 & 20.0 & $\mathrm{~cm}$. \\
\hline Head over the weir. & $\mathrm{H}$ & varied & 3.95 & 8.55 & $\mathrm{~cm}$. \\
\hline Head over the pipe. & $\mathrm{H}_{\mathrm{p}}$ & varied & 1.6 & 17.3 & $\mathrm{~cm}$. \\
\hline Discharge. & $\mathrm{Q}$ & varied & 5.91 & 17.37 & $\mathrm{Lit} / \mathrm{sec}$. \\
\hline Downstream Froude No. & $\mathrm{Fe}$ & varied & 0.06 & 0.25 & - \\
\hline
\end{tabular}

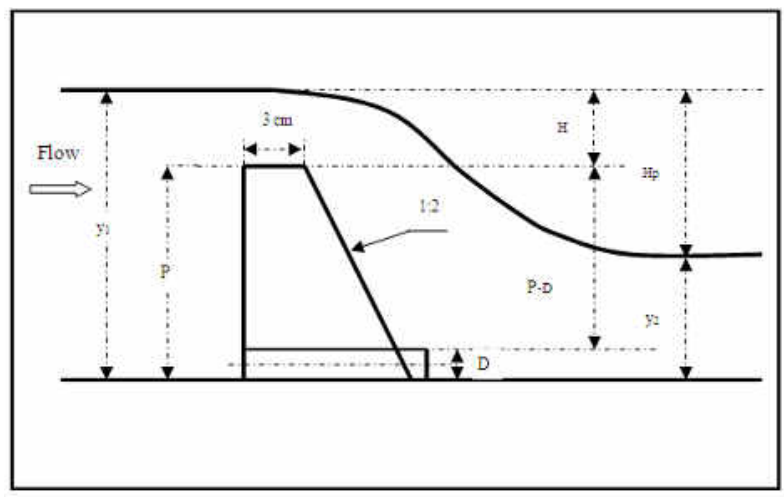

Fig. 1. Definition sketch of the used model.

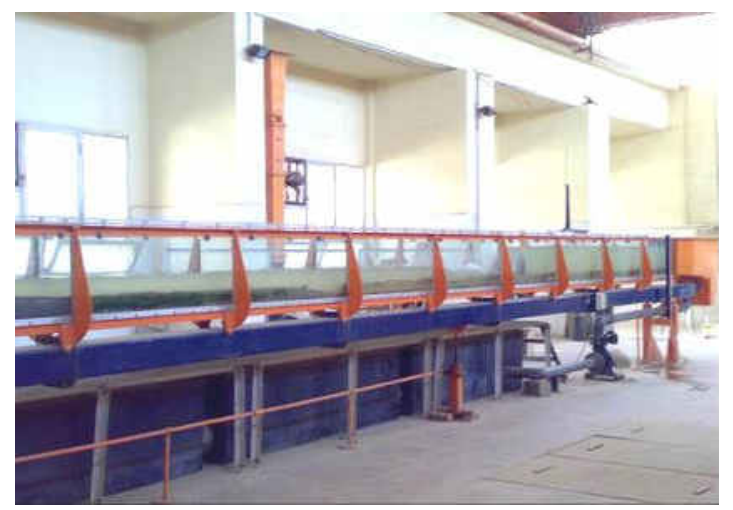

Photo 1. The flume and the used model. 


\section{Theoretical approaches}

\subsection{Discharge equations based on energy principals}

Flow over a rectangular weir without lateral contractions and a non- submerged hydraulic jump can be described by [1]:

$$
\begin{aligned}
& Q_{a c t w}=\frac{2}{3} C_{d w} B \sqrt{2 g} H^{1.5} \text { or, } \quad \text { (suppressed weir) } \\
& Q_{a c t w}=C_{1} H^{1.5} \\
& Q_{a c t w}=\frac{2}{3} C_{d w}(B-0.1 n H) \sqrt{2 g} H^{1.5} \text { (contracted-weir) }
\end{aligned}
$$

In which $Q_{a c t w}$ is the actual discharge passes over the weir, $C_{d w}$ is the coefficient of discharge, $\mathrm{B}$ is the width of the weir, $\mathrm{n}$ is the number of end contractions, $g$ is the gravitational acceleration, and $\mathrm{H}$ is the water head over the weir. Also, Flow through the pipe is governed by the following equation for the orifice discharge [1]:

$$
\begin{aligned}
& Q_{a c t p}=\left(\frac{\pi}{4} D^{2}\right) C_{d p} \sqrt{2 g H_{P}} \text { or, } \\
& Q_{a c t p}=C_{2} H^{0.5}
\end{aligned}
$$

In which $Q_{a c t p}$ is the actual discharge through the pipe, $C_{d p}$ is the coefficient of discharge, and $\mathrm{Hp}$ is the difference of head of water on the pipe, see Fig. (1).

From the geometry shown in Fig. (1),

$$
H_{p}=H+\left(P-y_{2}\right)
$$

If $y_{2}$ ranges from $D$ to $P$ to satisfy the condition of free flow through clear over-fall weir and submerged pipes,

$$
\begin{array}{ll}
\text { Maximum } & H_{p}=H+(P-D), \\
\text { Minimum } & H_{p}=H
\end{array}
$$

Thus, any relationship controls the flow passing over combined structure $\left(Q_{a c t}\right)$ consisted of weir and pipe must use these equations to illustrate the interaction that may be happened. The following equation may be used in providing relationship between discharge over weir and that through pipes:

$$
Q_{a c t}=Q_{a c t w}+Q_{a c t p}
$$

or

$$
C_{d} Q_{t h}=C_{d w} Q_{t h w}+C_{d p} Q_{t h p}
$$

where $Q_{t h}, C_{d}$, are the theoretical discharge and the coefficient of discharge of combined devices, respectively and $Q_{t h w}, Q_{t h p}$ are the theoretical discharges passing over the weir and that passing through the pipe respectively. From Eq. (7), one can easily get the following form: 


$$
C_{d}=C_{d w} \frac{Q_{t h w}}{Q_{t h}}+C_{d p} \frac{Q_{t h p}}{Q_{t h}}
$$

The values of $C_{d}, C_{d w}$ and $C_{d p}$ may be experimentally estimated.

\subsection{Dimensional analysis}

A physically pertinent relationship between the discharge and the other dependent parameters may be found by dimensional analysis. The non-dimensional relationship is also useful for checking the sensitivity of the different parameters which affect the phenomenon [9]. The functional relationship of the discharge Q may be expressed by:

$$
Q=\Phi_{l}\left(\mathrm{~B}, b, P, H, H_{p}, y_{1}, y_{2}, D, \rho, \mu, g\right)
$$

where, width of the channel (B), width of the weir (b), height of the weir $(\mathrm{P})$, upstream water head over the weir $(\mathrm{H})$, upstream water depth $\left(\mathrm{y}_{1}\right)$, downstream water depth $\left(\mathrm{y}_{2}\right)$, diameter of the pipe (D), water density $(\rho)$, dynamic viscosity of the fluid $(\mu)$, gravitational acceleration $(\mathrm{g})$. Using $\pi$-theorem and applying the properties of dimensional analysis, it yields;

$$
\phi_{2}\left(\frac{b}{B}, \frac{b}{D}, \frac{P}{D}, \frac{H}{D}, \frac{H_{p}}{D}, \frac{y_{1}}{D}, \frac{y_{2}}{D}, \frac{Q}{D^{2.5} \sqrt{g}}, \frac{\rho Q}{\mu D}\right)=0
$$

In which $\frac{\rho Q}{D \mu}=$ Reynolds Number. In open channel flow, Reynolds Number effect may be neglected [9]. The width of the weir is constant, so, Eq. (10) may be takes the following form:

$$
\frac{q}{D^{1.5} \sqrt{2 g}}=\phi_{3}\left(\frac{b H}{B y_{1}}, \frac{H+D}{P}, \frac{H}{D}, \frac{y_{1}-y_{2}}{D}\right)
$$

The left hand term represents the dimensionless discharge value and will be called $C_{D}$ for simplicity, and $\mathrm{q}$ is the discharge per unit width of weir crest.

\section{Results and discussions}

\subsection{Flow characteristics}

Figure (2) shows the variation of upstream water depth, $y_{1}$, with the downstream water depth, $y_{2}$, at weir height equals to $14.6 \mathrm{~cm}$, pipe diameter equals to $7.0 \mathrm{~cm}$ and discharge of 10.84 lit./sec. (as an illustrative example). The upstream water depth remains constant for free flow through weir without pipes, while it is affected when the downstream water depth become higher than the pipe diameter, for the piped weir. The rate of increase in upstream water depth is higher when the weir is contracted than it is suppressed (un-contracted). This might be explained as the submergence of the pipe reduces the acting head and the passing discharge. So, the discharge over the weir crest should increase by increasing the upstream water depth. 


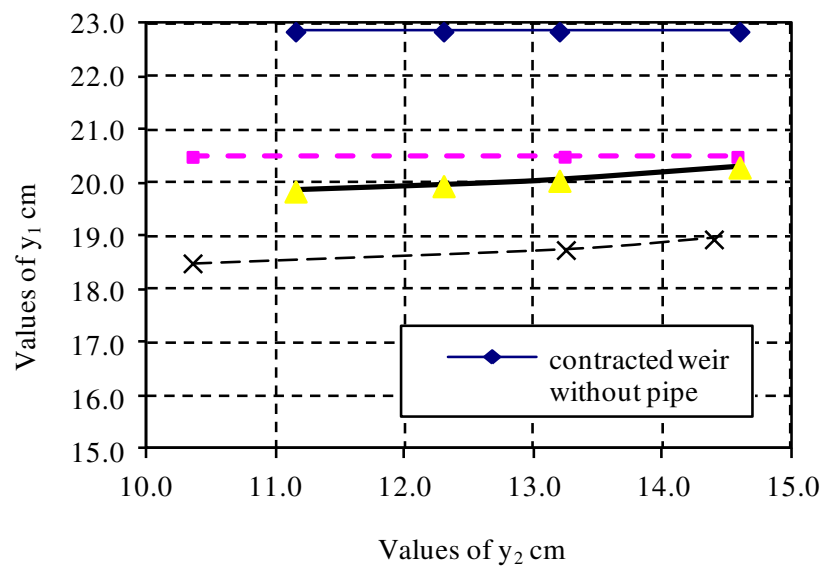

Fig. 2. Variation of $\mathrm{y}_{1}$ with $\mathrm{y}_{2}$ at weir height $P=14.6 \mathrm{~cm}$ and pipe diameter $D=$ $7 \mathrm{~cm}, \mathrm{Q}=10.84 \mathrm{lit} / \mathrm{sec}$

Water surface profiles for both piped and that without pipes weirs are represented in Fig. (3). The length of hydraulic jump was noticed and measured on the longitudinal scale of the glass lab channel. For the case of submerged pipe-free weir, it can be seen that the hydraulic jump behind the weir with opening occurs nearer to the weir than that at weir without pipes. This may be happen as when the flow falls only over the weir, the total momentum upstream the jump is higher than that for piped weir. Also, the upstream water depth is higher for weir without pipes than that at piped weir, and for the contracted than that for the un-contracted. So, the existence of bottom pipe to pass discharge increases the canal conveyance efficiency upstream of the weir.

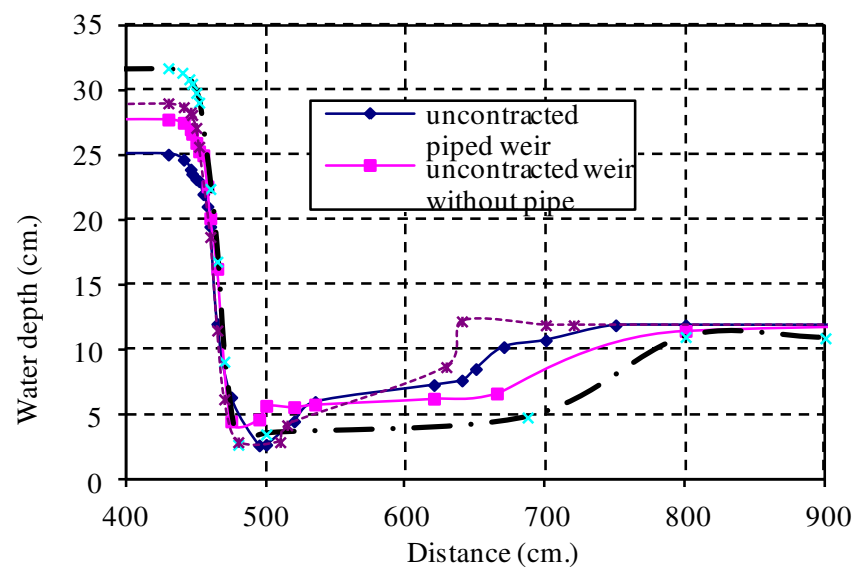

Fig. 3. Water surface profiles over weir at $P=20 \mathrm{~cm}, D=7.0 \mathrm{~cm}$ and $Q=15.94$ lit $/ \mathrm{sec}$.

For the same weir height, the variation of upstream water level with discharge for different pipe diameters is shown in Figs. $(4-a)$, and $(4-b)$. With reference to the figures, it can be concluded that for the same opening, as the discharge increase the upstream water depth increases. 


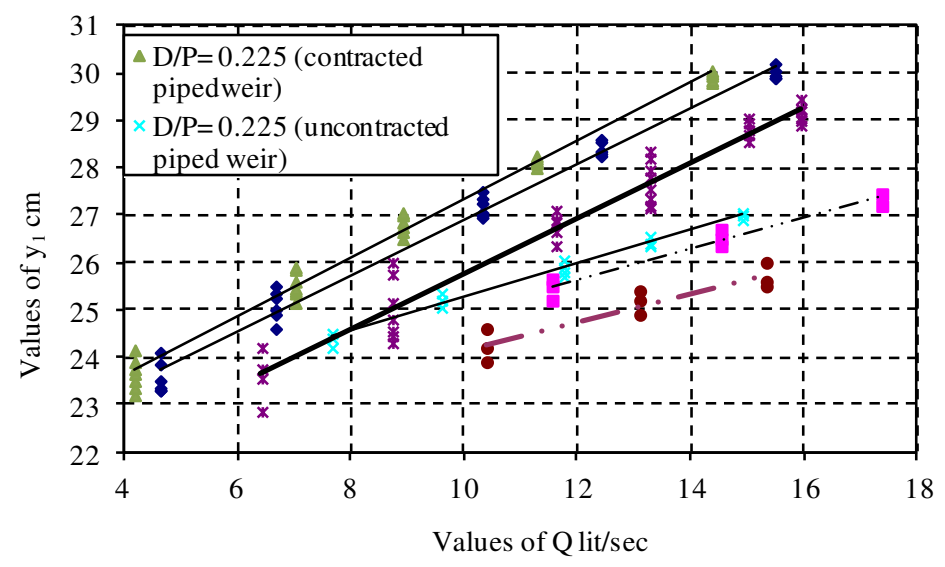

Fig. (4-a). Variation of upstream water depth with discharge for contracted piped weir and un-contracted piped weir with height $\mathrm{P}=20 \mathrm{~cm}$.

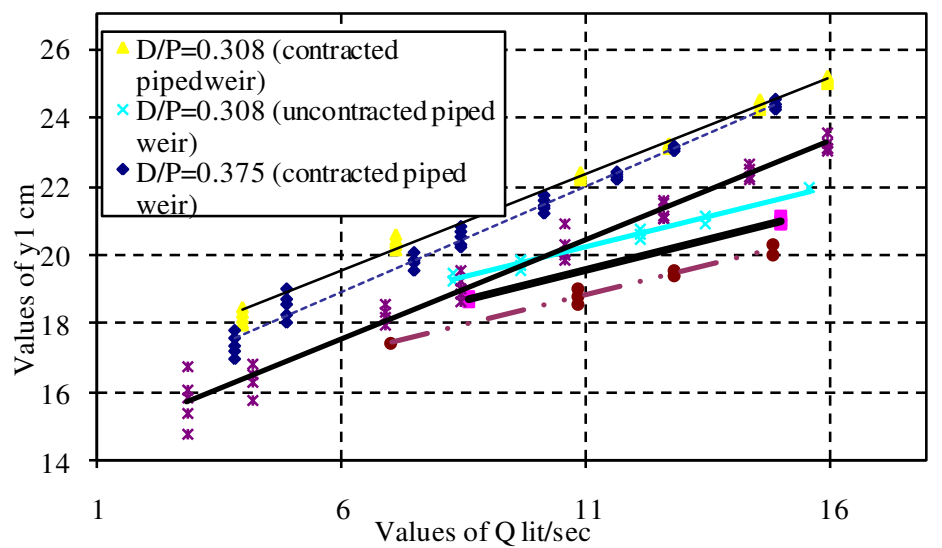

Fig. (4-b). Variation of upstream water depth with discharge for contracted piped weir and un-contracted piped weir with height $\mathrm{P}=14.6 \mathrm{~cm}$.

The effect of different dimensionless parameters derived earlier, Eq. (11), on the discharge as a dimensionless value is explored. Figures (5 to 8) show the variation of dimensionless discharge value $C_{D}$ with the dimensionless parameters $(H+D) / P, H / D$ $\left(y_{1}-y_{2}\right) / D$, and $b H /\left(B y_{1}\right)$ for different pipe diameters respectively. It is shown that the dimensionless discharge values increase linearly with these parameters. 


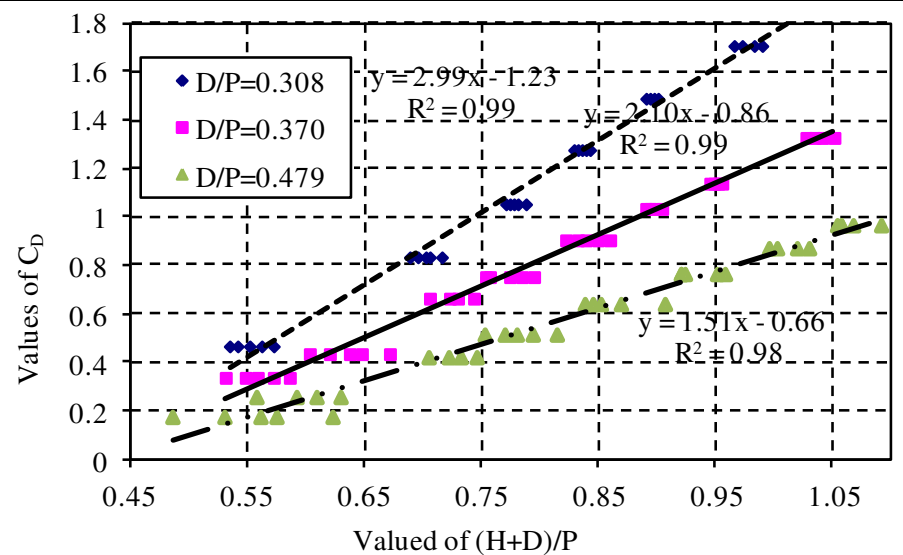

Fig. (5-a). Variation of dimensionless discharge value with dimensionless parameter $(H+D) / P$ at contracted piped weir with height $\mathrm{P}=14.6 \mathrm{~cm}$.

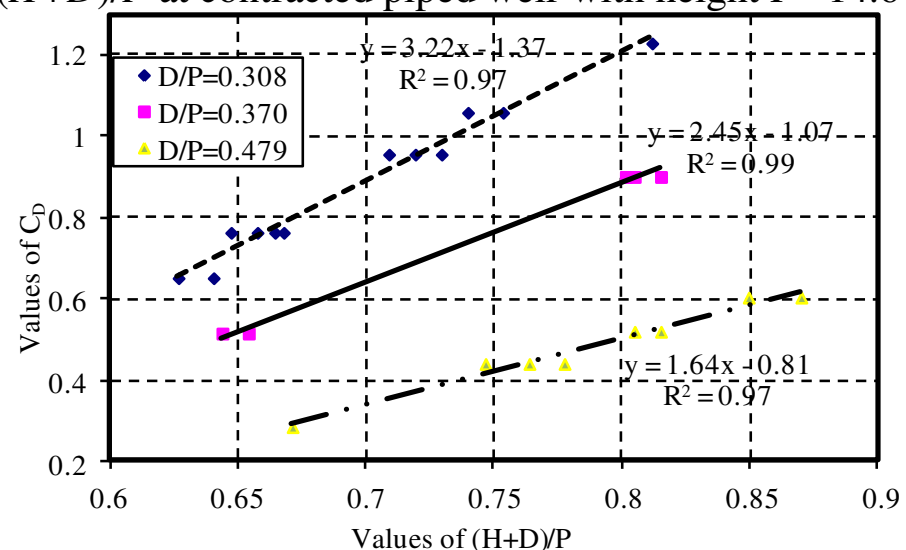

Fig. (5-b). Variation of dimensionless discharge value with dimensionless parameter $(H+D) / P$ at un-contracted piped weir with height $\mathrm{P}=14.6 \mathrm{~cm}$.

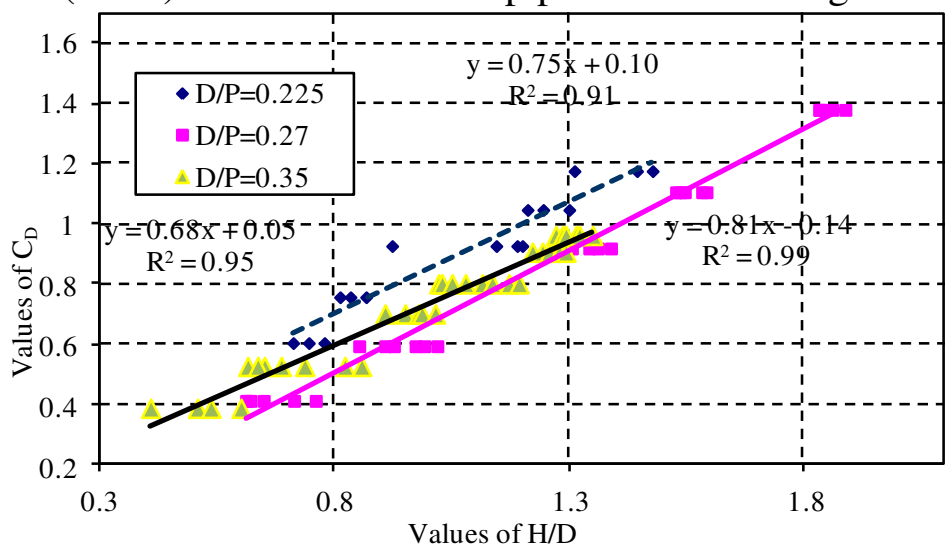

Fig. (6-a). Variation of dimensionless discharge value with dimensionless parameter $H / D$ at contracted piped weir with height $\mathrm{P}=20 \mathrm{~cm}$. 


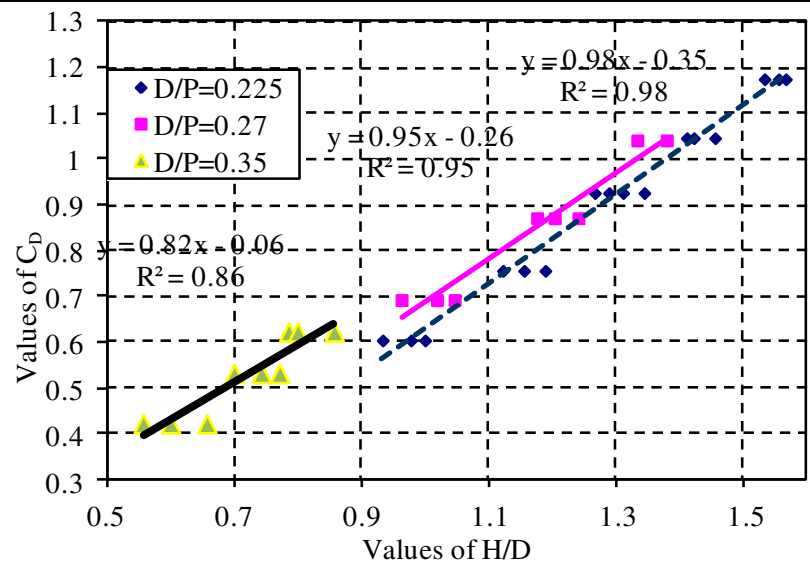

Fig. (6-b). Variation of dimensionless discharge value with dimensionless parameter $H / D$ at un-contracted piped weir with height $\mathrm{P}=20 \mathrm{~cm}$.

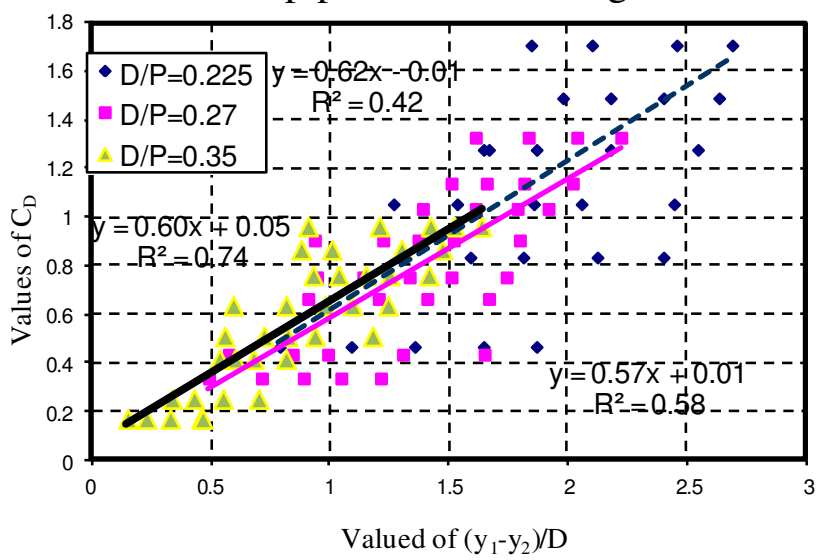

Fig. (7-a). Variation of dimensionless discharge value with dimensionless parameter $\left(y_{1-} y_{2}\right) / D$ at contracted piped weir with height $\mathrm{P}=20 \mathrm{~cm}$.

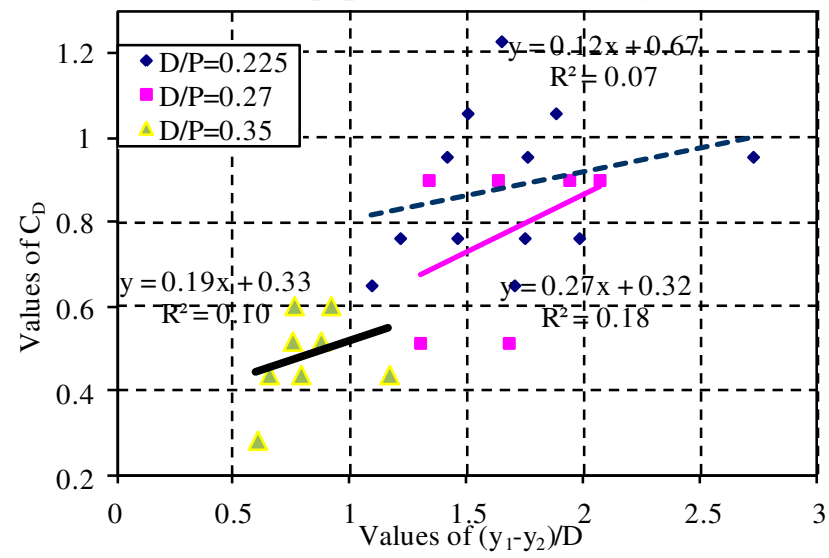

Fig. (7-b). Variation of dimensionless discharge value with dimensionless parameter $\left(y_{1-} y_{2}\right) / D$ at un-contracted piped weir with height $\mathrm{P}=20 \mathrm{~cm}$. 


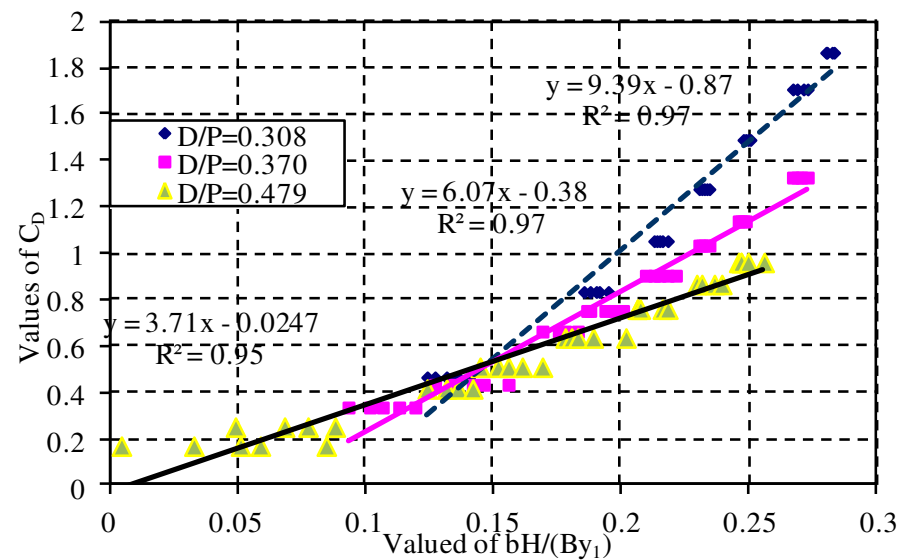

Fig. (8-a). Variation of dimensionless discharge value with dimensionless parameter $b H /\left(B y_{1}\right)$ at contracted piped weir with height $\mathrm{P}=14.6 \mathrm{~cm}$.

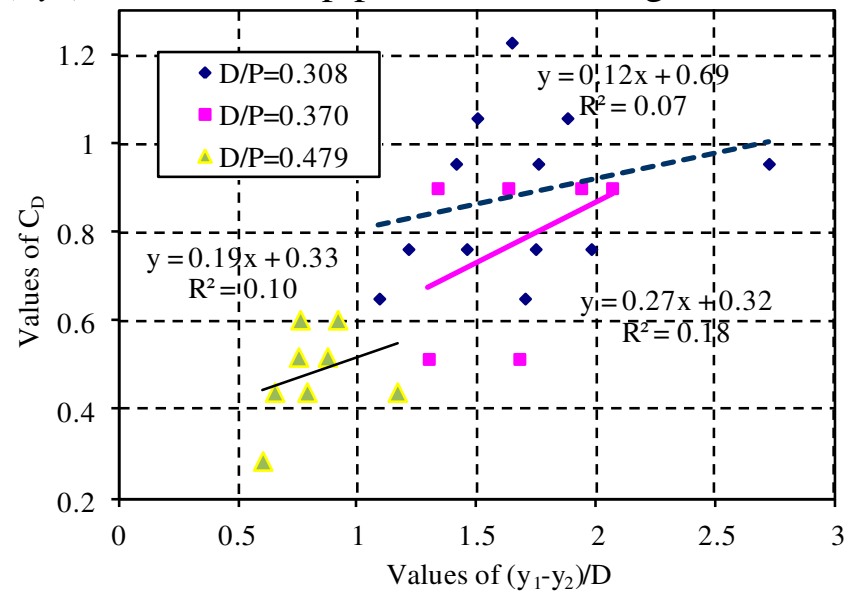

Fig. (8-b). Variation of dimensionless discharge value with dimensionless parameter $b H /\left(B y_{1}\right)$ at un-contracted piped weir with height $\mathrm{P}=14.6 \mathrm{~cm}$.

The multiple regression analysis is used for correlating the different dimensionless parameters shown in Eq. (11) to develop an empirical equation for computing the discharge over clear over fall contracted weir with submerged bottom pipes. The developed equation can be expressed as follows;

$\frac{q}{D^{1.5} \sqrt{2 g}}=-0.35+1.06 \frac{H+D}{P}+0.86 \frac{H}{D}+0.06 \frac{y_{1}-y_{2}}{D}-3.78 \frac{b H}{B y_{1}}$

The coefficient of correlation $\mathrm{R}^{2}$ and the standard error in estimating these parameters are 0.992 and 0.036 , respectively for the range of studied parameters.

A multiple regression analysis is used for correlating the different dimensionless parameters shown in Eq. (11) to develop an empirical equation for computing the discharge over clear over fall un-contracted weir with submerged bottom pipes. The developed equation can be expressed as follows; 


$$
\frac{q}{D^{1.5} \sqrt{2 g}}=-0.39+1.13 \frac{H+D}{P}+0.97 \frac{H}{D}+0.05 \frac{y_{1}-y_{2}}{D}-2.87 \frac{b H}{B y_{1}}
$$

The coefficient of correlation $\mathrm{R}^{2}$ and the standard error in estimating these parameters are 0.979 and 0.037 , respectively for the range of studied parameters.

Based on Eq.(8) and the measured data, using the regression analysis, one can estimate the average values of $C_{d w}$ and $C_{d p}$ and consequently the total discharge passing through the combined structure of piped weir. It is found for the range of the experiments that:

1. For un-contracted piped weir:

$C_{d}=0.75 \frac{Q_{t h e}}{Q_{t h}}+1.05 \frac{Q_{t h p}}{Q_{t h}}$

with $\mathrm{R}^{2}=0.996$, and $\mathrm{SEE}=0.042$ for the range of studied parameters.

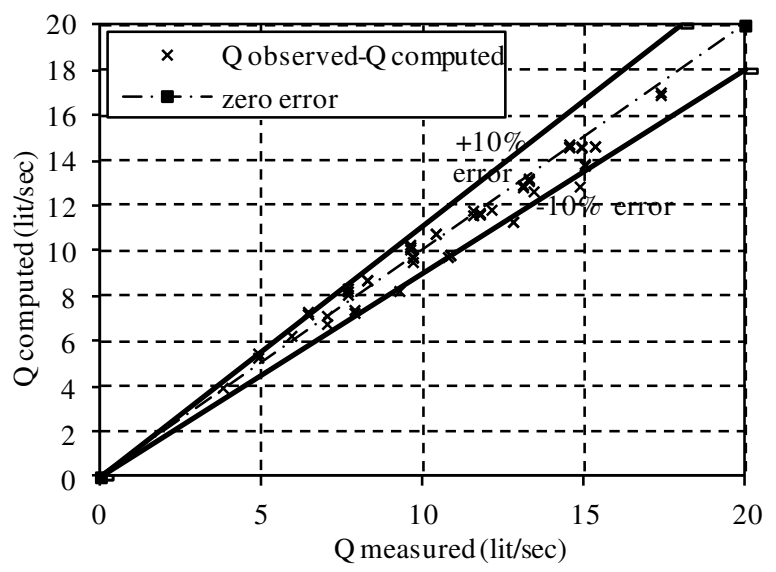

Fig. (9). Relationship between computed discharges using Eq. (14) versus measured ones for un-contracted piped weir.

2. For contracted piped weir:

$$
C_{d}=0.72 \frac{Q_{t h e}}{Q_{t h}}+0.90 \frac{Q_{t h p}}{Q_{t h}}
$$

with $\mathrm{R}^{2}=0.996$, and $\mathrm{SEE}=0.055$ for the range of studied parameters. 


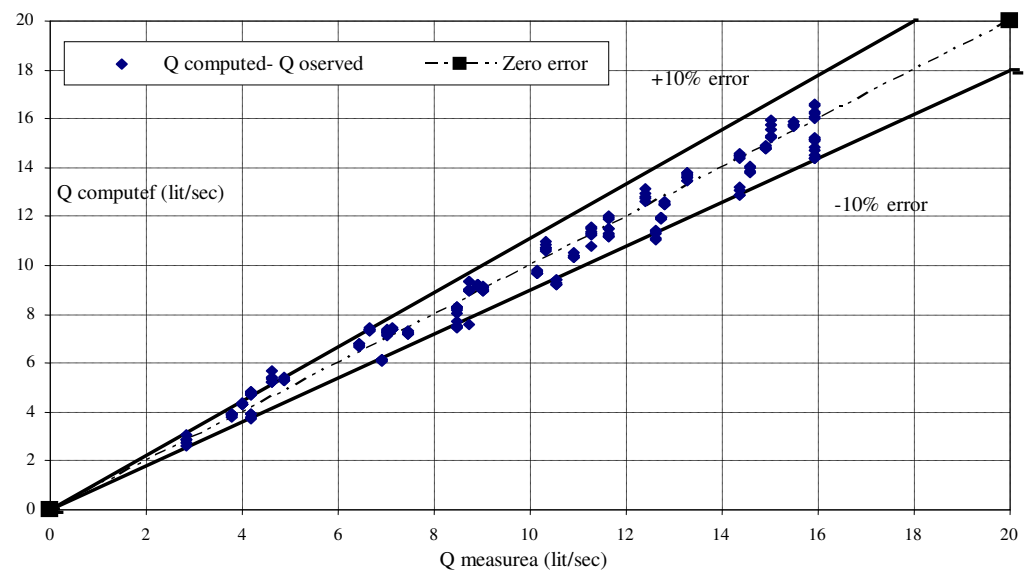

Fig. (10). Relationship between computed discharges using Eq. (15) versus measured ones for contracted piped weir.

Based on Eq.(1b,3b) and the measured data, using the regression analysis, one can estimate the average values of $C_{1}$, and $C_{2}$ and consequently the total discharge passing with the combined structure (weir and bottom opening). It is found for the range of the experiments that the values of $C_{1}$, and $C_{2}$ are:

- Piped weirs with $\mathrm{D} / \mathrm{P}=(\mathbf{0 . 2 2 5 , 0 . 3 0 8 )}$ :

1. For un-contracted piped weir:

$Q_{a c t}=0.742 H^{1.5}+0.373 H_{p}^{0.5}$

with $\mathrm{R}^{2}=0.988$, and $\mathrm{SEE}=0.274$ for the range of studied parameters.

2. For contracted piped weir:

$Q_{a c t}=0.424 H^{1.5}+0.464 H_{p}^{0.5}$

with $\mathrm{R}^{2}=0.996$, and SEE $=0.055$ for the range of studied parameters.

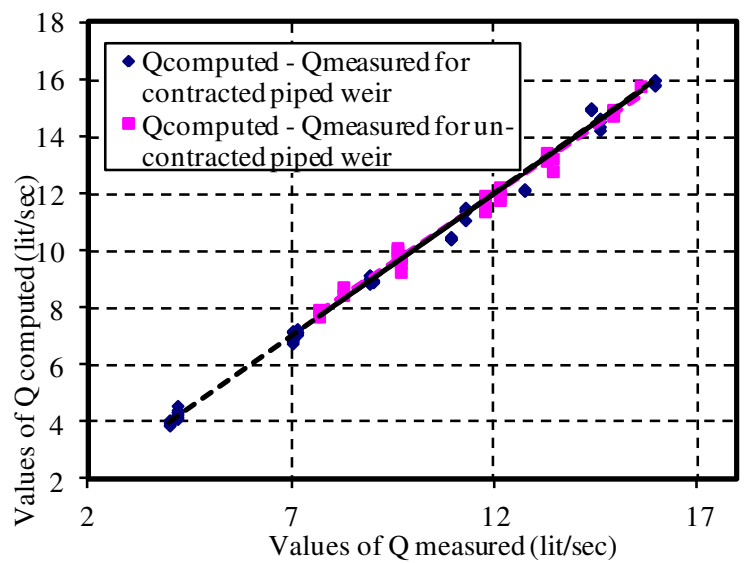

Fig. (11). Relationship between computed discharges using Eq. (16), Eq. (17) versus measured ones for contracted piped weir. 
- Piped weirs with $\mathrm{D} / \mathrm{P}=(\mathbf{0 . 2 7 0}, 0.370)$ :

1. For un-contracted piped weir:

$$
Q_{a c t}=0.74 H^{1.5}+0.82 H_{p}^{0.5}
$$

where standard error $\mathrm{R}^{2}=0.967$, and $\mathrm{SEE}=0.528$ for the range of studied parameters.

2. For contracted piped weir:

$$
Q_{a c t}=0.41 H^{1.5}+0.79 H_{p}^{0.5}
$$

where standard error $\mathrm{R}^{2}=0.988$, and $\mathrm{SEE}=0.405$ for the range of studied parameters.

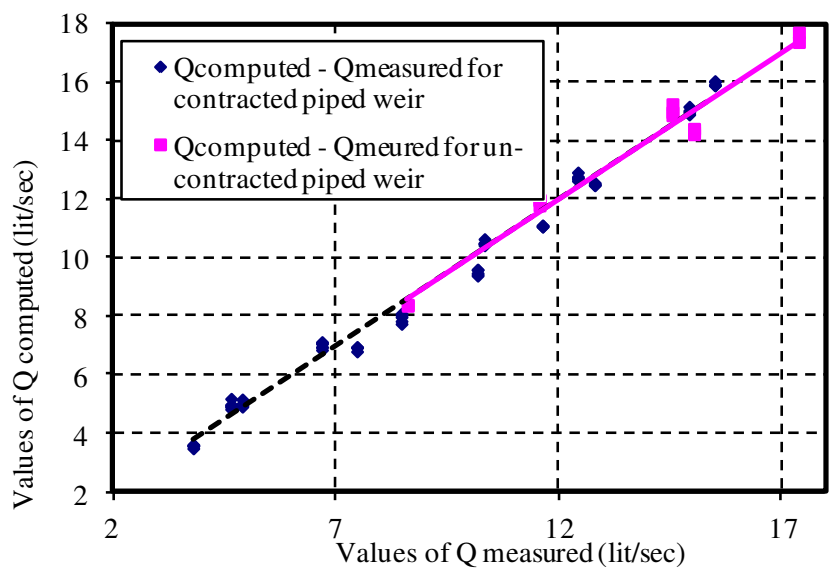

Fig. (12). Relationship between computed discharges using Eq. (18), Eq. (19) versus measured ones for contracted and un-contracted piped weir

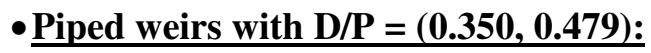

1. For un-contracted piped weir:

$$
Q_{a c t}=0.84 H^{1.5}+1.32 H_{p}^{0.5}
$$

Where standard error $\mathrm{R}^{2}=0.935$, and $\mathrm{SEE}=0.618$ for the range of studied parameters.

2. For contracted piped weir:

$$
Q_{a c t}=0.39 H^{1.5}+1.67 H_{p}^{0.5}
$$

Where standard error $\mathrm{R}^{2}=0.961$, and $\mathrm{SEE}=0.816$ for the range of studied parameters. 


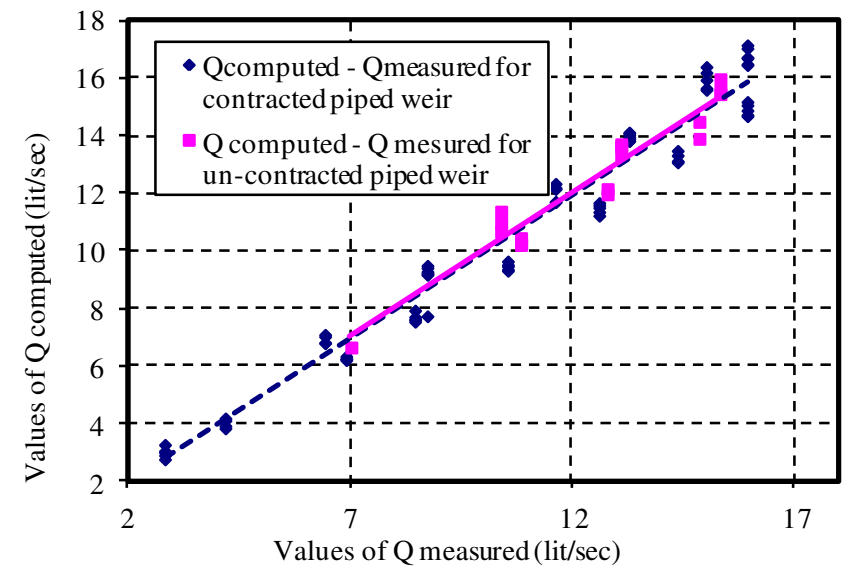

Fig. (13). Relationship between computed discharges using Eq. (20), Eq. (21) versus measured ones for contracted and un-contracted piped weir.

Table 3.

Values of $\mathrm{Cd}_{\mathrm{w}}$ and $\mathrm{Cd}_{\mathrm{p}}$ estimated from relation among $\mathrm{Q}, \mathrm{H}^{1.5}$ and $\mathrm{Hp}^{0.5}$

\begin{tabular}{|c|c|c|c|c|c|c|}
\hline \multirow{2}{*}{$\begin{array}{c}\text { Case of } \\
\text { contraction }\end{array}$} & \multicolumn{6}{|c|}{$\mathrm{D} / \mathrm{P}$} \\
\cline { 2 - 7 } & $0.225,0.308$ & \multicolumn{2}{|c|}{$0.270,0.370$} & \multicolumn{2}{c|}{$0.350,0.479$} \\
\hline $\begin{array}{c}\text { Un contracted } \\
\text { piped weir }\end{array}$ & 0.84 & 0.53 & 0.83 & 0.81 & 0.95 & 0.78 \\
\hline $\begin{array}{c}\text { Contracted piped } \\
\text { weir }\end{array}$ & 0.80 & 0.63 & 0.77 & 0.78 & 0.73 & 0.98 \\
\hline
\end{tabular}

\section{Conclusions}

The finding from this research may have practical applications especially when operating the existing bottom pipes to increase the conveyance efficiency of the channel upstream the weirs and also to increase the discharge passing to the downstream of the channel. The following main conclusions may be drawn:

1- The division of flow passing with combined structure affected the flow characteristics downstream, where for weir with bottom pipes; the hydraulic jump behind it is formed at shorter distance than that with weir without bottom pipes.

2- Operating the bottom pipes for passing flow with that passing over the weir crest decreases the upstream water depth, consequently increases the conveyance efficiency of the upstream channel and increases the flow passing capacity of the weir.

3- The downstream water depth affects the upstream water depth for weir with bottom pipes when the pipes become submerged.

4- Based on the dimensional analysis and the energy concepts, equations are developed for computing the discharge through the combined device for the same conditions of derivation. 
5- The relationships among $\mathrm{Hp}, \mathrm{H}$ and $\mathrm{Q}$ depend mainly on the diameter of the pipe installed in the bottom of the weir as well as the dimension of the weir.

\section{References}

[1] Abdel Halim, N. A., Sherif, M. M., and El-Zaher, A. S.,"On the Fayoum Weirs with Orifices ", J. of Eng. and Applied Scie., Faculty of Eng., Cairo Univ., Egypt, Vol. 38, No. 5, pp. 893-904. 1991.

[2] Abouzeid, G., "Improvement of The Hydraulic Performance of Sharp-crested Side Weirs in Circular Channels", International Water Technology Conference, IWTC8 2004, Egypt. pp. 499-509, 2004.

[3] Abozeid, G., Mohamed, H. I., and Shehata, S. M., (2010), "Hydraulic of Clear Overfall Weirs With Bottom-Openings", J. of Faculty of Engineering, Assiut University, 38(1), pp 19-28.

[4] Alhamid, A. A., "Analysis and Formulation of Flow through Combined V-noch-gate Device" J. of Hyd. Res., Vol. 37, No. 5, pp 697-705, 1999.

[5] Alhamid, A. A., Negm, A. M. and Al-Brahim, A. M.,"Discharge Equation for Proposed Self-Cleaning device" J. of King Saud Univ., Eng. Scie., Riyadh, Saudi Arabia, Vol. 9, No.1, pp. 13-24, 1997.

[6] Ansar, M.,"Discussion of Simultaneous Flow Over and Under a Gate" J. of Irrig.\& Drain. Eng., pp. 325-328, 2001.

[7] Bos, M. G., Clemmens, A. J. and Replogle, J. A.,"Design of long-throated structures for flow measurement", Irrig. and Drain. Syst.1, pp. 75-92, 1986.

[8] El-Belasy, A.M., Study of the discharge capacity of the Damietta Branch for high flows. HRI report No. 108/2004. 2004.

[9] El-Belasy, A.M., Developing formulae for combined weir and orifice (case study: ElFayoum weirs), Alexandria, Engineering Journal, Vol.52, pp. 763-768, 2013.

[10]Ferro, V.,"Simultaneous Flow over and Under a Gate", J. of Irrig.\& Drain. Eng., Vol. 126, No. 3, pp.190-193, 2000.

[11]Göğüş, M.; Defne, Z. and Özkandemir, V.,"Broad-crested weirs with rectangular compound cross sections”, J. of Irrig. and Drain., Vol. 132, No. 3, pp. 272-280, 2006.

[12] Hager, W. H. and Schwalt, M., "Broad-crested weir”, J. of Irrig. \& Drain. Eng., Vol. 120, No. 1, pp. 13-26, 1994.

[13] Mohamed, H. I.'Discharge measurement in trapezoidal lined canals utilizing horizontal and vertical transitions", $9^{\text {th }}$ Int. Water Tech. Conf. (IWTC9), Sharm El-Sheikh, Egypt, 2005.

[14] Negm, A. M.,"Discharge Prediction Model for Simultaneous Underflow-Overflow" Proc. $6^{\text {th }}$ Int. Symp. On Flow Modeling and Turbulence Measurements, Florida, USA, 8 10, sep., Balkema Publishers, pp.665-670, 1996.

[15] Negm, A. M.,"Characteristics of Simultaneous overflow-submerged underflow (unequal contractions)", Eng. Bulletin, Faculty of Eng., Ain Shams Univ., Cairo, Egypt, Vol. 35, No. 1, pp (137-154, 2000.

[16] Negm, A. M.,"Experimental Investigation on Simultaneous Flow through Combined Box Culverts and Over Contracted Broad-Crested Weirs" Proc. $2^{\text {nd }}$ Int. Conf. for Advanced Trends in Eng., 7-9, April, Faculty of Eng., Al-Minia Univ., Egypt, 2002.

[17] Negm, A. M., Abdel-Aal, G. M., Matin, A. M. and Alhamid, A. A.,"Discharge Equation 
for Free and Submerged Flow through Combined Weir" Proc. Of al-Azhar Eng. $3^{\text {rd }}$ Int. Conf., Faculty of Eng., Al-Azhar Univ., Cairo, Egypt, pp. 456-470, 1997.

[18] Negm, A. M., Abdel-Aal, G. M., Matin, A. M. and Alhamid, A. A.,"Generalized Discharge Equation for Proposed Simultaneous Flow Structures" Proc. $6^{\text {th }}$ Of al-Azhar Eng. Int. Conf.,1-4 Sept., Faculty of Eng., Al-Azhar Univ., Cairo, Egypt, pp. 247-257, 2000.

[19] Negm, A. M., Al-Brahim, A. M., Alhamid, A. A.,"Combined-free Flow over Weirs and below Gates", J. of Hyd. Res., Vol. 40, No. 3, pp.359-365, 2002.

[20] Samani, J. M. V. and Mazaheri M.,"Combined Flow over Weir and under Gate" J. of Hyd. Eng., Vol. 35, No. 3, pp. 224-227, 2009.

[21] Sargison, J. E. and Percy, A.,"Hydraulics of broad-crested weirs with varying side slopes”, J. of Irrig. \& Drain., Vol. 135, No. 1, pp. 115-118, 2009.

[22] USBR, "Water Measurement Manual", United States Department of the interior, Bureau of Reclamation, second Edition, Denver, col., revised reprint 1984, pp. 7- 42, 2003.

[23] Wolters, W., ghobrial, N. S. and Eisa, M.,"Calibration of weirs in The Fayoum, Egypt", Irrig. \& Drain. Syst., 1, pp. 173-185, 1987.

\section{الخصائص الهيدروليكية للسريان على الهدارات الحرة ذات القتحات السقلية

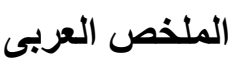

تستخدم الهدارات حرة السقوط فى العديد من الأغر اض الهيدروليكية مثل توزيع المياه وقياس معدلات

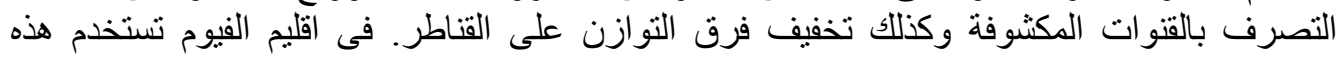

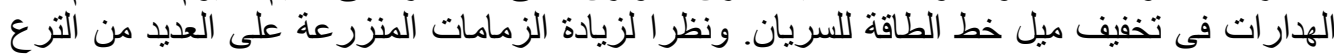

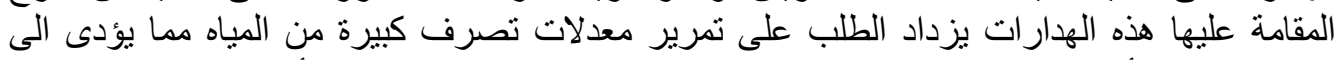

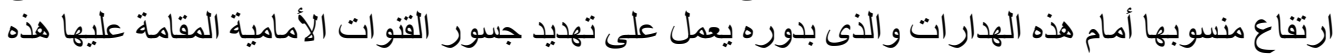

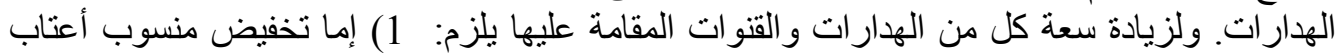

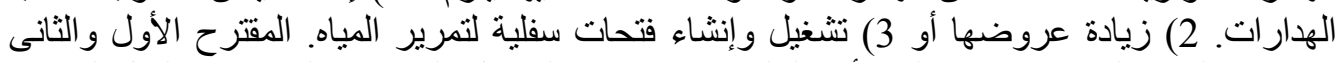

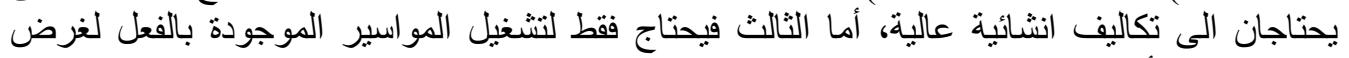

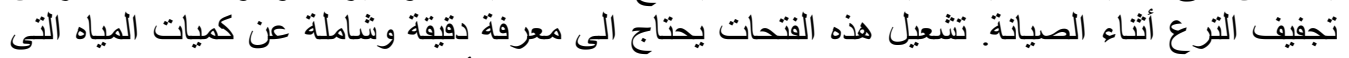

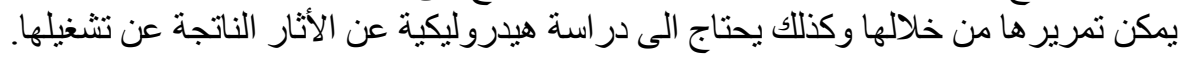
تهنم الدراسة الحالية بمحاولة معرفة سلوك السريان وكذلك ايجاد معادلات تطبيقية لتقدير معدل

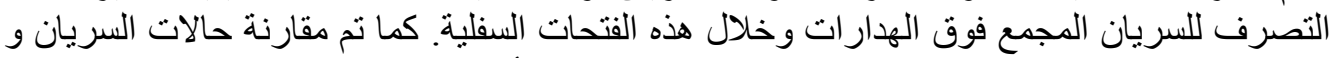

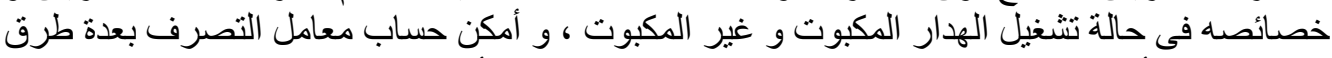

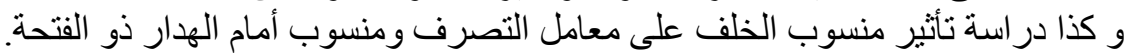
أجريت الدر استة عمليا على نماذج للهدار ات الحرة المكبوتة و غير المكبوتة - contracted weir, un contracted weir)

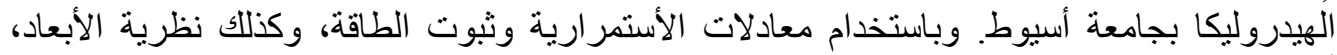

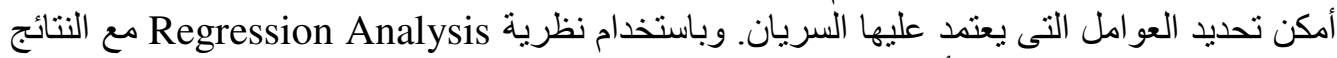

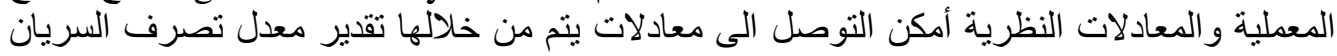

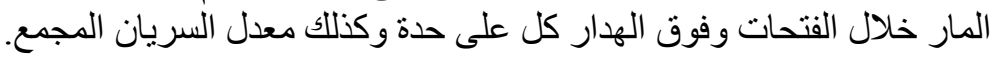

